\title{
Professional Nurses' Knowledge level on Type II Diabetes Mellitus at Selected teaching and Training Hospitals in the Central Region of Ghana
}

Anita Afua Davies ${ }^{1 *}$ and Christiana Buxton ${ }^{2}$

${ }^{1}$ Lecturer, School of Nursing, University of Cape coast, Cape Coast, Ghana

${ }^{2}$ Lecturer, Department of Mathematics and Science Education, University of Cape Coast, Ghana

"Corresponding author: Anita Afua Davies, Lecturer, MSc Nursing, RN, School of Nursing, University of Cape coast, Cape Coast, Ghana, Tel : +233246452789 ; Email: adavies@ucc.edu.gh

Received date: July 16, 2014, Accepted date: January 26, 2015, Publication date: January 28, 2015

Copyright: ( 2015Davies AA, et al. This is an open-access article distributed under the terms of the Creative Commons Attribution License, which permits unrestricted use, distribution, and reproduction in any medium, provided the original author and source are credited.

\begin{abstract}
Background: Diabetes Mellitus is a global public health concern for many nations in the 21st Century with approximately 246 million people worldwide living with diabetes. A large number of research studies have it that nurses' knowledge on diabetes mellitus is poor and that there is the need to increase their knowledge level for effective management of patients with diabetes mellitus. In some cases, nurses' knowledge was adequate but they lacked knowledge in certain aspects of diabetes mellitus care especially, diabetic complications and insulin advancements. Also, there was a general notion in Sub-Saharan Africa that health care workers were insufficiently trained in chronic disease management.
\end{abstract}

Methods: With this in mind, there was the need to find out the knowledge level of nurses in the Central Region of Ghana, particularly the Central Regional Hospital, the District Hospital and the University Hospital. To arrive at that a modified version of The Michigan Diabetes Research and Training Centre's Brief Diabetic Knowledge Test was administered.

Results: Fourty- four $44(32.4 \%)$ of the respondents' knowledge was good.However, knowledge level in the area of diabetic complications was generally poor among majority $(68.4 \%)$ of the respondents.

Conclusions: It is recommended that nurses continue to upgrade their knowledge in the area of diabetes mellitus, particularly in the area of diabetes complications and insulin advancements.

Keywords: Nurses; Knowledge; Michigan diabetes knowledge test; Type II diabetes mellitus; Professionals; Selected; Teaching and training hospitals

\section{Introduction}

Diabetes Mellitus is a global public health concern for many nations in the 21st Century and approximately 246 million people worldwide have diabetes. Almost $6 \%$ the world's adult population have it. About $80 \%$ of these clients live in the developing countries, of which $40 \%$ are in the 40-59 year group [1]. It is one of the most common chronic diseases in the Western world since 2007 [2]. According to [3] the number of people with diabetes has reached 366 million contributing to approximately 4.6 million of deaths. King et al (1998) cited in [4] predicted that by the year 2025 , the number of patients with diabetes mellitus would increase to 300 million [2].

It is becoming an increasing worldwide health problem [5]. The 23 million people represent $8 \%$ of the population. Of this 11.5 million are women and 12 million are men, representing $10.2 \%$ and $11.2 \%$ of the population respectively. It is the seventh leading cause of death and is likely to be underreported as a cause of death [6]. China has the second largest number of people suffering from diabetes in the world. According to $\mathrm{WHO}$, rapid changes in lifestyle and socio-economic developments in Asia will cause major increases in the prevalence of diabetes mellitus in mainland China and India.In 2003, the number of people with diabetes mellitus exceeded 30 million [7].

Apart from the limited number of professional health staff in most developing countries, it has been indicated that health workers are insufficiently trained in chronic disease management $[8,9]$. It has also been reported that the effort of healthcare professionals has traditionally been spent on developing methods for ensuring compliance with prescribed therapeutic regimens rather than understanding the complexity and reality of managing diabetes on a daily basis [10]. As such it has been suggested that, nurses need to enhance their practical knowledge further by attending courses [4].

The Eastern and the Middle East are the regions with the highest diabetes prevalence rates. In 2007, India had the world's largest diabetes population, followed by China, the USA, Russia, Germany, Japan, Pakistan, Brazil, Mexico and Egypt [1]. The highest prediabetes prevalence is in the European region, with $9 \%$ of the adult population being at significant risk of developing type II diabetes mellitus. This escalating diabetes prevalence is underpinned by factors such as an aging population, unhealthy diet, overweight, and obesity, as well as lack of physical activity [1].

Diabetes prevalence is increasing globally and Sub-Saharan Africa is no exception which, according to [9] has the highest growth rates and is among the highest worldwide. Health workers are insufficiently trained in chronic disease management resulting in severe 
complications and a reduced life expectancy. The health system does not reach a considerable portion of the population, has a focus on emergencies and infectious diseases, and is frequently limited in staff and infrastructure [9]. With diverse challenges, health authorities in Sub-Saharan Africa and international donors need robust data on epidemiology and impact of diabetes [11]. Studies on Diabetes Mellitus in Sub-Saharan Africa are remarkably scarce. Understanding manifestations and associated factors however is essential to guide diagnosis, management and prevention of diabetes mellitus type II [9].

In 2010, 12.1 million people were estimated to be living with diabetes in Africa and this is projected to increase to 23.9 million by 2030. In Sub-Saharan Africa, this trend is emerging in a region grappling with high rates of communicable diseases including the highest global prevalence of HIV, Tuberculosis and Malaria. Impaired glucose tolerance and impaired fasting glucose are predictors of the incidence of type II diabetes mellitus. Prevalence of these suggests that the type II diabetes mellitus is likely to increase further in several countries in the region, including Cameroun, Ghana and Guinea [11]. Non communicable diseases are taking an equally severe, if not more toll on the health of Nigerians than communicable diseases. The mortality and morbidity of acute metabolic complications of diabetes mellitus, particularly diabetic ketoacidosis and hyperosmolar hyperglycemic syndrome are unacceptably high in Nigeria [12].

At an urban site in Ghana, with a sample size of 4735 and a participation rate of $75 \%$ the prevalence rate of type II diabetes mellitus was $6.4 \%$ with $69.9 \%$ undiagnosed. The prevalence of increased glucose tolerance was $10.7 \%$ and the prevalence of increased fasting glucose was $6 \%$ [11]. In 2003 the prevalence of type II diabetes mellitus rose to $17.9 \%$ [11]. There has been scattered report of successful attempts to improve diabetes care delivery and outcome. A team based restructuring of care in Ghana, including in particular nurse-led patient education, resulted in reduced diabetes-related admission rates even that it was funded by a foreign Nongovernmental organization, Tropical Health and Education Trust [13].

Ghana Health Service Report $[14,15]$ suggest that health promotion is being seriously embarked on and these are seen to be indicators of the prevention of non-communicable diseases such as diabetes mellitus. Ghana is said to have reached an epidemic where diabetes mellitus is concerned [16] and with researches indicating that knowledge of diabetes mellitus is inadequate among health care workers, it will be necessary to evaluate the knowledge level of Ghanaian nurses on diabetes mellitus.

Ghana's health system is ill-equipped to tackle the country's double burden of infectious and chronic diseases [17]. Statistics, gathered at a regional hospital in Ghana, shows a steady rise in the number of patients who visit the diabetic clinic for review each year. In 2011 the number of patients who visited the clinic for review was 7134. In 2012 the number rose to 8630. As at May, 2013 about 4444 clients had already visited the clinic for review $[18,19]$. The question is how prepared are the professional nurses to handle these patients?

\section{Literature Review}

Diabetes Mellitus locally termed "esikyere yeriba", an Akan word in Ghana which literally means "sugar disease", is a disease defined as a chronic illness [7] in which the Islets of Langerhans of the endocrine pancreas, fail to secrete insulin, a hormone necessary to convert excess glucose into glycogen. This is stored in the liver and when the body needs it, it is converted to glucose for the body's need [2,5]. There are four types of diabetes mellitus which are type I diabetes, type II diabetes, gestational diabetes and diabetes associated with other conditions or Syndrome [4,5].

Diabetes is a chronic disease requiring lifelong medical and nursing intervention and lifestyleadjustment [20]. The importance of regular follow-up of patients with the health care provider is of great significance in averting any long term complications [21]. With the alarming soaring statistics of diabetes mellitus, the role of nurses in helping patients to control associated morbidity and mortality is becoming increasingly important. Nurses, on the front line, can screen patients for early diabetes identification, recognize and initiate corrective measures for inadequate treatment regimens, help patients set and achieve therapeutic goals, and assess diabetes-related complications as they arise.

Diabetic foot disease and its related morbidity and mortality, although preventable has become a serious global burden. It has been reported that the lifetime risk of a patient with diabetes mellitus developing a foot ulcer could be as high as $25 \%$ and that every 30 seconds a lower limb is lost as a consequence of diabetes mellitus [22].

Diabetes is largely preventable especially type II diabetes and this is where health education and public awareness becomes critical. Health Care Workers especially nurses constitute important stake holders for the effective delivery of diabetic care and diabetic education [23].Studies have shown that ward nurses are the patient's most frequent contact when it comes to the management of diabetes mellitus [13]. Diabetes self-management is a challenge for both clients and health-care professionals. Healthcare professionals need to understand and address modifiable behaviour-specific variables [1]

Diabetes mellitus in the African continent is hugely affected by epidemiological factors [23] and issues of health care economics [13] and accurate epidemiological studies are often logistically and financially difficult. There continues to be an increasing number of people moving into urban areas from rural environments and this migration is inevitably associated with a shift in lifestyle from a relatively healthy traditional pattern to the urban scenario of increased food quantity, reduced quality, low levels of exercise, smoking and increased alcohol availability [13].

Studies have been carried out to determine the knowledge of nurses in diverse settings among many specialties of nursing. Knowledge of diabetes among student nurses [24] and health personnel is poor. This demands the initiation of educational programmes $[3,23,25,26]$.

Ahmed et al. [3], suggest more hours of training in diabetes especially in the area of insulin and its new advancement. The content of education should be dynamic and needs to reflect current evidence and practice guidelines and expert consensus supports the need for specialized diabetic nurses and educational training beyond academic preparation for the primary instructors on the diabetes team. The one educating has to be evaluated in terms of the person's ability and qualities which should be clinical, pedagogical and personal more than the actual content and quality of the intervention.

Incidence of diabetes is on the increase [26]. It is a growing public health problem in the world [26]. Diabetes is largely preventable [26]. It is important to step up the knowledge levels of health personnel especially nurses since they are the first point of call when it comes to diabetes management, so that effective education as well as care of the diabetic is well taken care of. Knowledge level of health workers on 
Page 3 of 6

diabetes especially nurses is not adequate to address the health needs of the population $[23,27]$.

Nurses play an important role in diabetes education as they constitute the largest group of health care professionals who have a lengthy contact with patients. Nurses combine science and art to provide health services and seek to eliminate physical, emotional, mental, social-cultural and spiritual patient needs. Since patient care is the first duty of nurses, they play an important role in the care of diabetes mellitus. In developed countries diabetes nursing is divided into several categories, including nurse practitioner, clinical nurse specialist, diabetes nurse, generalist nurse and each of them has clear duties. For example, nurse practitioner focuses on health promotion and disease prevention activities including patient education and consulting $[28,29]$. It is obvious that with the increasing prevalence of diabetes and its complications, there is undeniable need to train nurse specialist with the requisite skills and knowledge in this field.

The need for nurses to play an active role in diabetes education has been discussed though evidence indicates that this role is not undertaken appropriately $[23,24]$. One way to reduce the morbidity and mortality from diabetes mellitus is to educate people with diabetes in self-care practices [26]. Lack of knowledge among health care providers has been found to be one of the major obstacles in the management of hyperglycemia in diabetic conditions. Ahmed, Jabber, Zuberi, Islam, Shamim [3], recognized a serious problem with regard to the inadequate knowledge of registered nurses regarding the management of diabetes mellitus.

Other studies have been carried out to determine the knowledge of nurses in diverse settings among many specialties of nursing. In some cases, medical nurses' knowledge was compared with that of surgical nurses. Though statistical significant in their knowledge levels, that of surgical nurses was lower. In some cases, the knowledge was adequate but they lacked knowledge in certain aspects of care of the patient [23]. Yet another study on nurses' understanding of diabetes is not of a desirable level to provide adequate care $[3,23]$.

The cutoff point acceptable for glycosulated haemoglobin is $<7.0 \%$. In their study, the average percentage for glycosulated haemoglobin was $7.54 \pm 1.03$. Exercise, medication, balancing diets is essential in diabetes mellitus. Glycemic control affects women's visual and memory learning [30]. Also health education and public awareness by health care workers is a key factor in the prevention of this chronic disease [26]. As the incidence, prevalence and diagnosis of diabetes mellitus increases, more people will require care from health professionals [26].

A study by [4] on nurses' perceived and actual level of diabetes mellitus revealedthat overall perceived knowledge was statistically significant and correlated with actual knowledge with a Pearson's coofficient of correlation being 0.32, ( $\mathrm{p}<0.005$ ). Lack of nurses' knowledge led to patients receiving inadequate health care instruction [4]. The higher the educational level of the nurse the better knowledge level of the nurse on diabetes mellitus [25]. Diabetes self-management education is a cornerstone of diabetes care. However, many diabetic patients in the United Arab Emirates (UAE) lack sufficient knowledge about their disease due to illiteracy[31].

Little information on the knowledge of nurses and indeed other health care professionals who care for patients with diabetes in Ghana is known. This study was to evaluate the knowledge level of nurses in the Cape Coast Metropolis.

\section{Methodology}

The study was a quantitative study, cross-sectional and descriptive in nature.The population and sample of professional nurses in a Teaching Hospital and two training centres for health personnel was 220. One hundred and thirty-six professional nurses consented to answer the questionnaire giving a response rate of $61.8 \%$.

The study instrument was a modified version of the Michigan Diabetes Research and Training Centre's Brief Diabetic Knowledge Test. It consists of 23 questions with options. Four questions on diet, five questions on tests, seven questions on diabetic complications and seven questions on diabetes medication. The questionnaire was examined by nurse managers of the three health facilities and also by the nurse in charge of the diabetic clinic in the regional hospital, examiner of the professional nurses' examination of Ghana.

\section{Data analysis}

Data was analyzed using the Statistical Package for the Social Sciences (SPSS) program, (version 20). Further analyses that were conducted included the cross tabulation and one way Analysis of Variance (ANOVA). A statistical significant level (p-value) of 0.05 was used in the study.

\section{Results}

The results centred on background information percentages of respondents' correct answers to the questions and knowledge level of the respondents in terms of adequacy. The demographics included length of time of training in the area of diabetes (Table 1).

\begin{tabular}{|c|c|c|}
\hline Variable/Statement & $\mathbf{n}$ & $\begin{array}{l}\text { Percenta } \\
\text { ge }(\%)\end{array}$ \\
\hline \multicolumn{3}{|l|}{ Gender } \\
\hline Female & 95 & 69.9 \\
\hline Male & 41 & 30.1 \\
\hline \multicolumn{3}{|l|}{ Age Groups (years) } \\
\hline $20-30$ & 90 & 66.2 \\
\hline $31-40$ & 25 & 18.4 \\
\hline $41-50$ & 12 & 8.8 \\
\hline $51-60$ & 9 & 6.6 \\
\hline \multicolumn{3}{|c|}{ Highest level in Nursing Training } \\
\hline SRN & 24 & 17.6 \\
\hline Diploma (RN) & 69 & 50.7 \\
\hline Degree & 31 & 22.8 \\
\hline \multicolumn{3}{|c|}{ Variable/Statement n Percentage (\%) } \\
\hline Post graduate & 9 & 6.6 \\
\hline Missing value & 3 & 2.2 \\
\hline \multicolumn{3}{|c|}{ Time spent on Diabetes Mellitus in Nursing School } \\
\hline$<1$ month & 87 & 64 \\
\hline
\end{tabular}


Page 4 of 6

\begin{tabular}{|l|l|l|}
\hline 1 month & 23 & 16.9 \\
\hline 1 Semester & 8 & 5.9 \\
\hline 2 Semesters & 14 & 10.3 \\
\hline 3 Semesters & 3 & 2.2 \\
\hline Missing value & 1 & 0.7 \\
\hline Work Experience as Nurse (years) & & \\
\hline $1-5$ & 91 & 66.9 \\
\hline $6-10$ & 3 & 2.2 \\
\hline $11-15$ & 8 & 5.9 \\
\hline $16-20$ & 4 & 2.9 \\
\hline$>20$ & 10 & 7.4 \\
\hline Current Job Position/Grade & & \\
\hline Staff Nurse & 60 & 44.1 \\
\hline Senior Staff Nurse & 36 & 26.5 \\
\hline Nursing Officer & 23 & 16.9 \\
\hline Senior Nursing Officer & 9 & 6.6 \\
\hline Principal Nursing Officer & 7 & 5.1 \\
\hline Deputy Director of Nursing Services & 1 & 0.7 \\
\hline
\end{tabular}

Table 1: Background information about Nurses.

Table 1 shows 95 (69.9\%) of female and 41 (30.1\%) of male participated in the study. More females participated in the study than males. This clearly shows the lack of male interest in the nursing profession. Also among 136 nurses selected for the study, 90 (66.2\%) nurses were aged 20-30 years whiles $25(18.4 \%)$ nurses were aged 31-40 years. Twelve (8.8\%) nurses were aged 41-50 years. Only 9 (6.6\%) nurses were aged 51-60 years. From the data above it could be seen that all nurses were adults and within the working population of Ghana.

On the issue of highest level in nursing training, majority 69 $(50.7 \%)$ nurses had attained diploma (RN). Also, 24 (17.6\%) nurses indicated that they had attained SRN certificate in nursing. The highest level qualification indicated by nurses was Post graduate. This was indicated by 9 (6.6\%). Also $31(22.8 \%)$ nurses indicated degree in nursing as their highest level in nursing training. All nurses selected for the study had attained the standard level of qualification to qualify as a nurse in Ghana.

Furthermore, when nurses were asked to indicate time spent on diabetes mellitus during their nursing training, 110 (80.9\%) nurses indicated that they did spend less than or equal to a month on teaching and learning of diabetes mellitus. However, 14 (10.3\%) nurses indicated that they did spend two semesters in studying diabetes mellitus in nursing school. In all, table two revealed that nurses have had some lessons on diabetes mellitus during their nursing school.

When nurses were asked on their working experience, majority 91 (66.9\%) nurses indicated that they had worked as a nurse for about 1-5 years. It was also revealed that $10(7.4 \%)$ nurses had also worked for more than 20 years. Also, 8 (5.9\%) nurses indicated that they had

worked as a nurse for 11-15 years whiles 4 (2.9\%) nurses indicated to have worked for 16-20 years. Only, 3 (2.2\%) nurses indicated to have worked for 6-10 years. Nurses sampled for the study all have had some level of experience to give professional view on the issue.

Majority, 60 (44.1\%) nurses indicated that they were staff nurses in their various departments. Also, 36 (26.5\%) nurses indicated that they had attained senior staff grade whiles $23(16.9 \%)$ nurses indicated to be nursing officers in their various departments. Furthermore there were 9 (6.6\%) nurses who were senior nursing officers and 7 (5.1\%) indicating to be principal nursing officers. Only, $1(0.7 \%)$ nurse indicated to be deputy director of nursing services as patriated in the study.Table 2 showing the number and percentages of correct responses to the questions.

\begin{tabular}{|c|c|}
\hline Item & $n(\%)$ \\
\hline The diabetes diet is & 72(52.9) \\
\hline Which of the following is highest in carbohydrate? & \begin{tabular}{|l|}
119 \\
$(87.5)$
\end{tabular} \\
\hline Which of the following is highest in fat? & $\begin{array}{l}103 \\
(75.7)\end{array}$ \\
\hline Which of the following is free food? & $56(41.2)$ \\
\hline Hemoglobin A1 test measures average glucose level in & $35(25.7)$ \\
\hline Which is the best method for testing blood glucose? & $\begin{array}{l}104 \\
(76.5)\end{array}$ \\
\hline Effect of unsweetened fruit juice on blood glucose & $41(30.1)$ \\
\hline Which should not be used to treat low glucose? & $23(16.9)$ \\
\hline Effect of exercise on blood glucose for a person good control & $\begin{array}{l}118 \\
(86.8)\end{array}$ \\
\hline Infection is likely to cause? & 106(77.9) \\
\hline The best way to take care of your feet is to & $99(72.8)$ \\
\hline Eating food lower in fat decreases your risk for & $\begin{array}{l}132 \\
(97.1)\end{array}$ \\
\hline Numbness and tingling may be symptoms of & $\begin{array}{l}122 \\
(89.7)\end{array}$ \\
\hline Which is usually not associated with Diabetes? & 125(91.9) \\
\hline Signs of ketoacidosis include & $43(31.6)$ \\
\hline Changes to make when you have flu? & $72(52.9)$ \\
\hline $\begin{array}{l}\text { If you have taken NPH or Lente, you may have an insulin reaction } \\
\text { in? }\end{array}$ & $58(42.6)$ \\
\hline $\begin{array}{l}\text { What do you do if you missed your insulin before breakfast but } \\
\text { remember just before lunch? }\end{array}$ & $91(66.9)$ \\
\hline If you are beginning to have an insulin reaction, you should? & $65(47.8)$ \\
\hline Low blood glucose may be caused by & $105(77.2)$ \\
\hline Morning insulin without taking breakfast will & $\begin{array}{l}107 \\
(78.7)\end{array}$ \\
\hline High blood glucose may be caused by & $110(80.9)$ \\
\hline
\end{tabular}


Insulin reaction is most likely to be caused by $50(36.8)$

Table 2: Frequency (\%) distribution of answers to questionnaire items $(\mathrm{N}=136)$.

The mean mark for correctly answered questions was $14.38(62.5 \%)$ for all the study participants. As shown in Table two, 14 out of the 23 questions were answered correctly by at least half of the total respondents. Some of these questions assessed respondents' knowledge on the causes of insulin reaction, low and high blood glucose, effects of unsweetened fruit juice on blood glucose and exercise on blood glucose for a person good control, what should not be used to treat low glucose among others (Table 2). The question that had the least number of respondents answering correctly 43 (31.6\%) assessed their knowledge on signs of Ketoacidosis. Majority of the respondents 132 (97.1\%) answered correctly the question that assessed their knowledge on the essence of eating food low in fat. Two questions were answered correctly by $52.9 \%$ of the respondents. These two questions assessed respondents' knowledge on what a diabetic diet is and changes to make when you have flu.

There is no significant difference between the age groups (Sig. vale $=0.24>p$ value $=0.05$ ), current Job position/grade (Sig. value $=0.44>$ $\mathrm{p}$ value $=0.05$ ) and Highest training in Nursing (Sig. value $=0.77>\mathrm{p}$ value $=0.05)$. Hence no significant difference exist between the groups even though there is a difference in the mean scores.

\section{Discussion}

The mean for correctly answered question was 14.38 (62.5\%) for all the study participants as shown in table i. The question that had the least number of respondents answering correctly 33 (31.6\%) assessed their knowledge on signs of Ketoacidosis. This is in line with [8] and Danquah, et al. [9], that health care workers in Sub-Saharan Africa lack knowledge in complicated conditions and that understanding manifestations and associated factors however, is essential to guide diagnosis, management and prevention of Diabetes Mellitus.Majority of the respondents 132 (97.1\%) answered correctly the question that assessed their knowledge on the essence of eating food low in fat.

It was observed that all respondents in the following groups: age group 41 to 50 years, Senior Nursing Officers, one month and three semesters training on Diabetes Mellitus at school had at least adequate knowledge on diabetes mellitus. Only respondents who had one month training on diabetes mellitus in school had at least good knowledge in diabetes mellitus. The one and only Deputy Director of Nursing Services had inadequate knowledge on diabetes mellitus. Generally the highest mean scores were obtained in the following groups: females, age group of 20 to 30 years, diploma (RN) holders in nursing, respondents who had training on Diabetes Mellitus for one semester at school, respondents who were Staff Nurses and respondents who had not received any formal training on Diabetes Mellitus apart from Nursing School Training.

Although the level of adequacy of knowledge on Diabetes Mellitus was not in line with researches by $[3,4,23,25-27,31]$ in which nurses had poor knowledge of diabetes mellitus, but supports that of Odili Eke [23] the nurses had adequate knowledge on Diabetes Mellitus but lack knowledge in certain aspects of care.

Further analysis was performed to investigate whether a significant difference existed between the groups with respect to their knowledge level in diabetes mellitus using one way Analysis of Variance (ANOVA). Some of the groups like gender, time spent on diabetes mellitus training in school and had any diabetes mellitus training apart from training school could not meet all the necessary assumptions to enable the use of one way Analysis of variance (ANOVA). There is no significant difference between the age groups (Sig. vale $=0.24>\mathrm{p}$ value $=0.05$ ), current Job position/grade (Sig. value $=0.44>\mathrm{p}$ value $=0.05$ ) and Highest training in Nursing (Sig. value $=0.77>\mathrm{p}$ value $=0.05$ ) Hence no significant difference exist between the groups even though there is a difference in mean scores. This is probably due to the fact that there were a lot of groups which is how Ghana finds itself and also that the group sizes was not large enough to show any significant difference.

\section{Conclusion}

This study sought to evaluate nurses' knowledge on Diabetes Mellitus in the Cape Coast Metropolis, particularly, the three health facilities where health personnel have practical training: the Central regional Hospital, the District Hospital and the University Hospital. Nurses in these hospitals who took part in the study were found to have the greater number 66 (48.5\%), having adequate knowledge level on diabetes mellitus. They however lacked knowledge in certain aspects of care. This was in the area of diabetic complications.

\section{Recommendations}

The nurses' knowledge were found to have a greater percentage being adequate. This is probably so because the questionnaires were left with the nurses and collected at the convenience of the researchers. They probably did not do independent work. Also unknown to the researchers, a more modern instrument existed which could have been used. Future research should use onethat focuses on diabetic complications and insulin advancements.

\section{References}

1. Ho AY, Berggren I, Dahlborg-Lyckhage E (2010) Diabetes empowerment related to Pender's Health Promotion Model: a meta-synthesis. Nurs Health Sci 12: 259-267.

2. Kosti M and Kanakari M (2012) Education and Diabetes Review. Health Science Journal (4).

3. Ahmed A, Jabbar A, Zuberi L, Islam M, Shamim K (2012) Diabetes related knowledge among residents and nurses: a multicenter study in Karachi, Pakistan. BMC Endocr Disord 12: 18.

4. Chan MF, Zang YL (2007) Nurses' perceived and actual level of diabetes mellitus knowledge: results of a cluster analysis. J Clin Nurs 16: 234-242.

5. Bare BG, Cheever KH, Hinkle JL and Smelter SC (2010) Brunner \& Suddarth's textbook of Medical - Surgical Nursing (12 ed). Philadelphia: Lippincott Williams \& Wilkins.

6. Eaton-Spiva L, Day A (2011) Effectiveness of a computerized educational module on nurses' knowledge and confidence level related to diabetes. J Nurses Staff Dev 27: 285-289.

7. Shi Q, Ostwald SK, Wang S (2010) Improving glycaemic control selfefficacy and glycaemic control behaviour in Chinese patients with type 2 diabetes mellitus: randomised controlled trial. J Clin Nurs 19: 398-404.

8. Mbanya JC, Kengne AP, Assah F (2006) Diabetes care in Africa. Lancet 368: 1628-1629.

9. Danquah I, Bedu-Addo G, Terpe KJ, Micah F, Amoako YA, et al. (2012) Diabetes mellitus type 2 in urban Ghana: characteristics and associated factors. BMC Public Health 12: 210. 
Citation: Davies AA and Buxton C (2015) Professional Nurses' Knowledge level on Type II Diabetes Mellitus at Selected teaching and Training Hospitals in the Central Region of Ghana. J Nurs Care 4: 229. doi:10.4172/2167-1168.1000229

Page 6 of 6

10. Ruston A, Smith A, Fernando B (2013) Diabetes in the workplace diabetic's perceptions and experiences of managing their disease at work: a qualitative study. BMC Public Health 13: 386.

11. Hall V, Thomsen RW, Henriksen O, Lohse N (2011) Diabetes in Sub Saharan Africa 1999-2011: epidemiology and public health implications. A systematic review. BMC Public Health 11: 564.

12. Balogun W, Adeleye J (2008) Strategies for prevention of hyperglycaemic emergencies in Nigeria. Ann Ib Postgrad Med 6: 27-30.

13. Gill GV, Mbanya JC, Ramaiya KL, Tesfaye S (2009) A sub-Saharan African perspective of diabetes. Diabetologia 52: 8-16.

14. Okertchiri JA (2011) Ghana has 4m Diabetics.

15. de Graft Aikins A, Anum A, Agyemang C, Addo J, Ogedegbe O (2012) Lay representations of chronic diseases in Ghana: implications for primary prevention. Ghana Med J 46: 59-68.

16. Annual Report: Central Regional Hospital, Ghana 2011

17. Annual Report: Central Regional Hospital, Ghana2012

18. Zolfaghari M, Mousavifar SA, Haghani H (2012) Mobile phone text messaging and Telephone follow-up in type 2 diabetic patients for 3 months: a comparative study. J Diabetes Metab Disord 11: 7.

19. Shrivastava SR, Shrivastava PS, Ramasamy J (2013) Role of self-care in management of diabetes mellitus. J Diabetes Metab Disord 12: 14.

20. Desalu OO, Salawu FK, Jimah AO, Adekoya OA, Busari OA, et al. (2011) Diabetic Foot Care: self Reported Knowledge and practice among Patients Attending Three Tertiary Hospitals in Nigeria. Ghana medical Journal 45: 60-65.
21. Odili VU and Eke I (2010) Knowledge of Diabetes Mellitus among Registered Nurses in

22. Benin City. International Journal of Health Research3 : 145-151.

23. Unadike BC (2010) Awareness and Knowledge about Diabetes Mellitus Amongst Nursing

24. Students in the Niger Delta of Nigeria. Middle East Journal of Nursing, 4 .

25. el-Deirawi KM, Zuraikat N (2001) Registered nurses' actual and perceived knowledge of diabetes mellitus. J Nurses Staff Dev 17: 5-11.

26. UnadikeBC and Etukumana EA (2010) Nurses Understanding about Diabetes in a Nigerian Hospital. Pak J Med Sci, 26 : 217-222.

27. Naheed T, Akbar N and Akbar N (2003) Is there Need of Specialized Diabetic Nurses in Pakistan? Pak J Med Sci 19 :75-79.

28. Peimani M, Tabatabaei-Malazy O, Pajouhi M (2010). Nurses' Role in Diabetes Care; A review. Iranian Journal of Diabetes and Lipid Disorders, 9:1-9.

29. Aalaa M, Malazy OT, Sanjari M, Peimani M, Mohajeri-Tehrani M (2012) Nurses' role in diabetic foot prevention and care; a review. J Diabetes Metab Disord 11: 24

30. Compeán-Ortiz LG, Gallegos EC, Gonzalez-Gonzalez JG, Gomez-Meza MV, Therrien B, et al. (2010) Cognitive performance associated with selfcare activities in Mexican adults with type 2 diabetes. Diabetes Educ 36: 268-275.

31. Al-Maskari F, El-Sadig M, Al-Kaabi JM, Afandi B, Nagelkerke N, et al. (2013) Knowledge, attitude and practices of diabetic patients in the United Arab Emirates. PLoS One 8: e52857. 